\title{
Trabecular Bone Score and Bone Density in Patients With Non- radiographic Axial Spondyloarthritis
}

Hesham Hamoud ( $\sim$ Hamoud.hesham@yahoo.com)

Rheumatology Department, Al-Azhar University, Cairo, Egypt https://orcid.org/0000-0002-1256-0588

Mohamed Ghit

Al-Azhar University Faculty of Medicine

Mohamad Ali

Al-Azhar University Faculty of Medicine

Islam Khaled

Al-Azhar University Faculty of Medicine

\section{Research article}

Keywords: Spondyloarthritis, Non-radiographic axial spondyloarthritis, Radiographic axial spondyloarthritis, Bone mineral density, Trabecular bone scores, Egypt

Posted Date: September 4th, 2020

DOI: https://doi.org/10.21203/rs.3.rs-71571/v1

License: (c) (i) This work is licensed under a Creative Commons Attribution 4.0 International License. Read Full License

Version of Record: A version of this preprint was published at Journal of Medical Science And clinical Research on November 23rd, 2020. See the published version at https://doi.org/10.18535/jmscr/v8i11.84. 


\section{Abstract}

\section{Background}

Spondyloarthritis $(\mathrm{SpA})$ represents a group of several inflammatory conditions. Ankylosing spondylitis (AS) and non-radiographic axial spondyloarthritis (nr-axSpA) are considered to belong to SpA family of diseases. The aim of our study is to evaluate bone mineral density (BMD) and trabecular bone scores (TBS) scores in patients suffering from nr-axSpA.

\section{Methods}

A cross-sectional study evaluating 160 patients. Inclusion criteria involved patients $18-45$ years of age, having clinical features of $\mathrm{SpA}$, and fulfilling Calin's criteria for inflammatory low back pain. Patients were divided into 3 groups; group A (nr-axSpA) patients, group B (radiographic axial spondyloarthritis (r-axSpA)) patients, and group C (mechanical low back pain).

\section{Results}

Female to male ratio was significantly higher in group A compared to group B $(63.3 \%$ vs. $36.7 \%)$ and $(23.33 \%$ vs. $76.7 \%)(p<0.001)$, respectively. While disease duration was significantly higher in group $B$ in comparison to groups $A$ and $C(47.65 \pm 7.15,18.56 \pm 6.55$, and 14.76 \pm 4.20$)(p<0.001)$, respectively. L1-L4 and L2-L4 TBS of groups $A$ and $B$ were significantly lower compared to group $C$ $(p<0.001)$. Additionally, a statistically significant decrease in BMD scores of L1-L4, femoral neck, and total hip bones was detected in group A compared to group C $(p<0.001)$.

\section{Conclusion}

Patients with nr-axSpA had a lower BMD and TBS compared to r-axSpA group (B) and control group (C), and it predominantly affected more females than males (3:1).

\section{Background}

Spondyloarthritis $(\mathrm{SpA})$ is a term that describes several rheumatic conditions affecting the joints and causing inflammation $[1,2]$. These rheumatic disorders include ankylosing spondylitis (AS), psoriatic arthritis (PsA), and others [1].

Axial spondyloarthritis (axSpA) refers to a condition that affects the axial skeleton and causes inflammation in the spine and/or sacroiliac joints (SIJs) leading to back pain and stiffness [1, 2]. Non-radiographic axial spondyloarthritis (nr-axSpA) has been recently described and was identified as part of the SpA family of diseases [3]. Both nr-axSpA and AS are considered as 2 stages of ax-SpA [2]. Estimates of disease progression reveal that $5.1 \%$ of patients progress from nr-axSpA to AS within 5 years and $19 \%$ within 10 years [4].

Predictors that influence spinal progression vary considerably among axSpA patients with syndesmophytes being considered as the strongest predictor of radiographic spinal progression [5]. As the diseases progresses, inflammation leads to new bone formation as well as bone resorption causing osteoporosis [6]. Therefore, changes in bone mass reflect severity of the inflammation [5]. The early inflammatory phase of axSpA does not cause structural damage to the SIJs, while at later stages, structural damage is visible on Xray scans [7].

Currently, there are no specific useful imaging techniques to diagnose and monitor osteoporosis in axSpA. Dual-energy X-ray absorptiometry (DXA) is the most widely implemented tool to measure bone mineral density (BMD) [7]. However, this technique comes with limitations associated with overestimation of results due to the presence of structural lesions $[7,8]$. Additionally, information regarding bone microarchitecture are not fully captured by BMD [9].

The trabecular bone score (TBS) is a novel non-invasive technique that is used to evaluate bone microarchitecture. It facilitates the early detection of osteoporosis through evaluation of lumbar spine DXA image [10]. The aim of the present study is to evaluate BMD and TBS scores in nr-axSpA patients.

\section{Methods}




\subsection{Study design}

This cross-sectional study investigated 160 patients suffering from chronic low back pain. Those patients were on the follow-up period with the lower back pain clinic of Al-Azhar University hospital, Damietta, Egypt.

\subsection{Patient and control groups}

Inclusion criteria for the study involved patients between 18-45 years of age, having clinical features of SpA (dactylitis, psoriasis, uveitis, and arthritis), and fulfilling Calin's criteria for inflammatory low back pain (age at onset $\leq 40$ years, insidious onset, back pain for $\geq 3$ months, associated with morning stiffness, and improvement with exercise); the latter criteria were fulfilled if at least 4 out of 5 parameters were present [11]. Patients were excluded if they were on systemic steroids bisphosphonates, or any medications that could affect bone metabolism for the preceding year. Additionally, subjects were excluded if they had degenerative changes in the sacroiliac joints (in one or both hips), osteitis condensans ilii, or diabetes mellitus.

Sacroiliac joint X-ray was investigated for the patient population. The results revealed that 50 subjects had sacroiliitis. Out of these, 20 were excluded from the investigation due to concomitant degenerative changes in one hip (3 patients) or both hips (5 patients), sacroiliac joints involvement ( 2 subjects), and osteitis condensans ilii (10 patients). Afterwards, magnetic resonance imaging (MRI) results of the remaining 110 subjects were examined to detect changes in the sacroiliac joint. The results revealed that 30 patients suffered from acute and chronic changes.

Subjects were then divided into 3 groups. The first group (group A) represented those patients suffering from sacroiliac joint changes as detected by the MRI (30 subjects). The second group (group B) included those patients with sacroiliitis (30 subjects), and the control group (group C) involved patients with mechanical low back pain (30 subjects).

\subsection{Magnetic resonance imaging for SIJs}

The Spondyloarthritis Research Consortium of Canada (SPARCC) MRI score was chosen due its high inter-reader reliability and sensitivity. Moreover, it has been reported to be the most reliable scoring system [12]. The SIJs were scored using the SPARCC method based on six consecutive coronal slices representing the synovial portion of the joint. Score ranges were as follows: Bone marrow edema (BME) (0-48), depth (0-12), and intensity $(0-12)$. The highest possible score is 72 [13-15].

The depth of BME is defined as positive when $1 \mathrm{~cm}$ or more of continuous edema extends in a horizontal direction away from the articular surface. Each SIJ was evaluated as a whole.

\subsection{Bone mineral density}

BMD was measured using DXA. BMD scans were performed with Lunar Prodigy Primo DXA system version 17 manufactured by GE healthcare (USA). BMD was measured at the lumbar spine (L1- L4), the left hip (femoral neck and total proximal femur), and the distal forearm. It is expressed as the number of grams of bone mineral per square centimeter $(\mathrm{g} / \mathrm{cm} 2)$ and $\mathrm{T}$ score.

\subsection{Trabecular bone score}

TBS provides a surrogate evaluation of bone microarchitecture by analyzing DXA images of the lumbar spine (L1-L4). Patients were divided into three TBS groups according to fracture risk based on a recent meta-analysis $[16,17]$ :

- High risk: TBS below 1.23

- Intermediate risk: TBS below 1.23-1.31

- Low risk: TBS above 1.31

Lumbar spine DXA images were reanalyzed in an operator-independent automated manner using TBS iNight software version 2.1 (Med-Imaps, Merignac, France).

\subsection{Statistical analysis}

The collected data was organized, tabulated and statistically analyzed using statistical package for social science (SPSS) version 22 (IBM® SPSS ${ }^{\circledR}$ Inc, USA). Quantitative data were expressed as mean \pm standard deviation (SD); while, qualitative data were expressed as frequency and percentage.

Page $3 / 12$ 
Independent samples t-test of significance was used when comparing between two means. Chi-square (X2) test of significance was used in order to compare proportions between two qualitative parameters. Student t-test was used for continuous normally distributed data and Mann-Whitney test was used for none normally distributed data. Comparison of categorical data was done using Chi-square or Fisher's exact test wherever appropriate. Quantitative data were examined by Kolmogrov Smirnov test for data normality.

Results were considered non-significant if $p>0.05$, significant if $p<0.05$, and highly significant if $p=0.01$.

\section{Results}

In this cross-sectional study, 160 subjects suffering from chronic inflammatory low back pain fulfilling Calin criteria were investigated. The baseline characteristics of the study population are illustrated in Table 1. 
Table 1

Baseline characteristics of the studied Groups.

\begin{tabular}{|c|c|c|c|c|c|}
\hline Variable & $\begin{array}{l}\text { Group A } \\
\text { (nr-ax SpA No. 30) }\end{array}$ & $\begin{array}{l}\text { Group B } \\
\text { (r-ax SpA No. 30) }\end{array}$ & $\begin{array}{l}\text { Group C } \\
\text { (Mechanical LBP } \\
\text { No. } 30 \text { ) }\end{array}$ & Test $^{*}$ & $P$ value \\
\hline \multirow[t]{2}{*}{ Age } & $34.50 \pm 4.93$ & $37.71 \pm 3.13$ & $36.20 \pm 3.28$ & 5.268 & 0.007 \\
\hline & $18-45$ & $31-44$ & $20-45$ & & \\
\hline Male & $11(36.7 \%)$ & $12(38.7 \%)$ & $23(76.7 \%)$ & 4.402 & 0.001 \\
\hline Female & $19(63.3 \%)$ & $19(61.3 \%)$ & $7(23.33 \%)$ & & \\
\hline \multirow[t]{2}{*}{ Weight (kg) } & $73.37 \pm 4.55$ & $75.52 \pm 4.09$ & $80.23 \pm 5.29$ & 17.033 & 0.001 \\
\hline & $65-84$ & $67-82$ & $70-92$ & & \\
\hline \multirow[t]{2}{*}{ Height } & $1.69 \pm 0.04$ & $1.69 \pm 0.04$ & $1.67 \pm 0.04$ & 1.816 & 0.169 \\
\hline & $1.62-1.76$ & $1.62-1.76$ & $1.59-1.74$ & & \\
\hline \multirow[t]{2}{*}{ BMI } & $25.64 \pm 1.19$ & $26.36 \pm 1.29$ & $28.65 \pm 2.02$ & 31.119 & 0.001 \\
\hline & $23.32-29.07$ & $22.9-29.8$ & $25.01-32.04$ & & \\
\hline \multirow[t]{2}{*}{ Disease duration } & $18.56 \pm 6.55$ & $47.65 \pm 7.15$ & $14.76 \pm 4.20$ & 406.127 & 0.001 \\
\hline & $3.00-26.00$ & 36.60 & $6.00-24.00$ & & \\
\hline \multirow[t]{2}{*}{ ESR } & $30.50 \pm 8.39$ & $31.39 \pm 8.97$ & $12.13 \pm 1.72$ & 4.801 & 0.010 \\
\hline & $15.00-50.00$ & $12-48$ & $9.00-15.00$ & & \\
\hline \multirow[t]{2}{*}{ CRP } & $10.83 \pm 4.72$ & $8.45 \pm 3.34$ & $4.17 \pm 0.87$ & 30.087 & 0.001 \\
\hline & $5.00-18.00$ & $4-16$ & $3.00-5.00$ & & \\
\hline \multicolumn{6}{|l|}{ Post hoc test (LSD) } \\
\hline & \multicolumn{2}{|l|}{ Group A VS Group B } & Group A VS Group C & \multicolumn{2}{|l|}{ Group B VS Group C } \\
\hline Sex & 0.001 & & 0.001 & 0.001 & \\
\hline Weight & 0.075 & & 0.001 & 0.001 & \\
\hline Height & 0.930 & & 0.113 & 0.093 & \\
\hline BMI & 0.071 & & 0.001 & 0.001 & \\
\hline Disease duration & 0.001 & & 0.001 & 0.001 & \\
\hline ESR & 0.697 & & 0.016 & 0.005 & \\
\hline CRP & 0.007 & & 0.001 & 0.001 & \\
\hline
\end{tabular}

With regard to gender distribution, the ratio of female to male patients in group A (nr-axSpA) $(63.3 \% \mathrm{vs.} 36.7 \%)$ was significantly higher than in group $B$ (radiographic axial SpA $(r-a x S p A))(23.33 \%$ vs. $76.7 \%)(p<0.001)$. Additionally, body mass index $(B M I)$ was found to be higher in group $C$ (control group) when compared to groups $A$ and $B(p<0.001)$.

Disease duration was significantly higher in group B in comparison to groups A and C 47.65 $\pm 7.15,18.56 \pm 6.55$, and $14.76 \pm 4.20$ ( $p<$ 0.001 ), respectively (Table 1). Moreover, inflammatory markers such as erythrocyte sedimentation rate (ESR) were higher in groups $A$ and $B$ relative to group $C 30.50 \pm 8.39,31.39 \pm 8.97$, and $12.13 \pm 1.72(p<0.005)$, respectively. Additionally, $c$-reactive protein (CRP) was higher in groups $A$ and $B$ when compared to group $C(p<0.001)$ (Table 1$)$. 
The BMD and T scores of the studied subjects are presented in Table 2. Results reveal a statistically significant decrease in BMD scores of L1-L4, femoral neck, and total hip bones, as well as T-scores of the same locations in group $A$ in comparison to group $C$ ( $p<$ 0.001). However, group A T-scores of L1-L4 and femoral neck were significantly lower than these in group $B(p<0.001)$ and significantly higher in group $C$ than in group $B(p<0.004)$ (Table 2$)$.

Table 2

Bone mineral density (DXA) and T score of the studied Groups.

\begin{tabular}{|c|c|c|c|c|c|c|c|c|c|c|c|c|c|c|}
\hline & \multicolumn{4}{|c|}{$\begin{array}{l}\text { Group A } \\
\text { (nr-ax SpA No. 30) }\end{array}$} & \multicolumn{4}{|c|}{$\begin{array}{l}\text { Group B } \\
\text { (r-ax SpA No. 30) }\end{array}$} & \multicolumn{4}{|c|}{$\begin{array}{l}\text { Group C } \\
\text { (Mechanical LBP No. 30) }\end{array}$} & \multicolumn{2}{|c|}{ One-way ANOVA } \\
\hline & Mean & SD & Min & Max & Mean & SD & Min & Max & Mean & SD & Min & Max & $f$ & $\begin{array}{l}P \\
\text { value }\end{array}$ \\
\hline $\begin{array}{l}\mathrm{L} 1-\mathrm{L} 4 \\
(\mathrm{~g} / \mathrm{cm} 2)\end{array}$ & 0.93 & 0.01 & 0.90 & 0.95 & 0.86 & 0.09 & 0.64 & 0.95 & 0.81 & 0.15 & 0.60 & 1.00 & 9.584 & $<.001$ \\
\hline $\begin{array}{l}\mathrm{L} 2-\mathrm{L} 4 \\
(\mathrm{~g} / \mathrm{cm} 2)\end{array}$ & 0.94 & 0.01 & 0.91 & 0.96 & 1.00 & 0.00 & 1.00 & 1.00 & 1.00 & 0.00 & 0.99 & 1.00 & 289.971 & $<.001$ \\
\hline $\begin{array}{l}\text { Femoral } \\
\text { neck }\end{array}$ & 0.87 & 0.01 & 0.84 & 0.90 & 0.81 & 0.08 & 0.64 & 0.90 & 0.73 & 0.10 & 0.58 & 0.96 & 27.630 & $<.001$ \\
\hline $\begin{array}{l}\text { Total } \\
\text { hip }\end{array}$ & 0.91 & 0.02 & 0.87 & 0.99 & 0.85 & 0.09 & 0.66 & 0.99 & 0.73 & 0.10 & 0.58 & 0.96 & 41.405 & $<.001$ \\
\hline $\begin{array}{l}\text { L1-L4 } \\
\text { (T- } \\
\text { score) }\end{array}$ & -1.58 & 0.19 & -2.00 & -1.20 & -1.22 & 0.54 & -2.00 & 0.80 & -1.18 & 0.43 & -2.00 & -0.60 & 8.288 & 0.001 \\
\hline $\begin{array}{l}\text { Femoral } \\
\text { neck (T- } \\
\text { score) }\end{array}$ & -0.46 & 0.12 & -0.80 & -0.30 & -0.37 & 0.11 & -0.60 & -0.10 & -0.14 & 0.14 & -0.50 & 0.20 & 53.380 & $<.001$ \\
\hline \multirow{2}{*}{$\begin{array}{l}\text { Total } \\
\text { hip (T- } \\
\text { score) }\end{array}$} & -0.61 & 0.25 & -1.40 & -0.20 & -0.51 & 0.27 & -1.40 & -0.10 & -0.33 & 0.26 & -0.80 & 0.20 & 9.244 & $<.001$ \\
\hline & \multicolumn{4}{|c|}{ Group A VS Group B } & & \multicolumn{3}{|c|}{ Group A VS Group C } & & & \multicolumn{4}{|c|}{ Group B VS Group C } \\
\hline $\begin{array}{l}\mathrm{L} 1-\mathrm{L} 4 \\
(\mathrm{~g} / \mathrm{cm} 2)\end{array}$ & \multicolumn{4}{|l|}{0.020} & & \multicolumn{3}{|l|}{0.001} & & & \multicolumn{4}{|l|}{0.045} \\
\hline $\begin{array}{l}\text { Femoral } \\
\text { neck }\end{array}$ & \multicolumn{4}{|l|}{0.004} & & \multicolumn{3}{|c|}{0.001} & & & \multicolumn{4}{|l|}{0.001} \\
\hline $\begin{array}{l}\text { Total } \\
\text { hip }\end{array}$ & \multicolumn{4}{|l|}{0.006} & & \multicolumn{3}{|l|}{0.001} & & & \multicolumn{4}{|l|}{0.001} \\
\hline $\begin{array}{l}\mathrm{L} 1-\mathrm{L} 4 \\
\text { (T- } \\
\text { score) }\end{array}$ & \multicolumn{4}{|l|}{0.001} & & \multicolumn{3}{|l|}{0.001} & & & \multicolumn{4}{|l|}{0.702} \\
\hline $\begin{array}{l}\text { Femoral } \\
\text { neck (T- } \\
\text { score) }\end{array}$ & \multicolumn{4}{|l|}{0.004} & & \multicolumn{3}{|l|}{0.001} & & & \multicolumn{4}{|l|}{0.001} \\
\hline $\begin{array}{l}\text { Total } \\
\text { hip (T- } \\
\text { score) }\end{array}$ & \multicolumn{4}{|l|}{0.125} & & \multicolumn{3}{|l|}{0.001} & & & \multicolumn{4}{|l|}{0.008} \\
\hline
\end{tabular}

TBS scores of the 3 groups are illustrated in Table 3. L1-L4 and L2-L4 TBS of groups A and B were significantly lower than in group C $(p<0.001)$. 
Table 3

TBS of the studied Groups.

\begin{tabular}{|c|c|c|c|c|c|c|c|c|c|c|c|c|c|c|}
\hline & \multicolumn{4}{|c|}{$\begin{array}{l}\text { Group A } \\
\text { (nr-ax SpA No. 30) }\end{array}$} & \multicolumn{4}{|c|}{$\begin{array}{l}\text { Group B } \\
\text { (r-ax SpA No. 30) }\end{array}$} & \multicolumn{4}{|c|}{$\begin{array}{l}\text { Group C } \\
\text { (Mechanical LBP No. 30) }\end{array}$} & \multicolumn{2}{|c|}{ One-way ANOVA } \\
\hline & Mean & SD & Min & Max & Mean & SD & Min & Max & Mean & SD & Min & Max & $\mathbf{F}$ & $P$ value \\
\hline L1-L4 & 1.28 & 0.04 & 1.21 & 1.36 & 1.29 & 0.04 & 1.22 & 1.37 & 1.33 & 0.02 & 1.29 & 1.36 & 14.093 & 0.001 \\
\hline L2-L4 & 1.27 & 0.05 & 1.19 & 1.35 & 1.28 & 0.05 & 1.21 & 1.36 & 1.31 & 0.02 & 1.28 & 1.35 & 12.959 & 0.001 \\
\hline & \multicolumn{5}{|c|}{ Group A VS Group B } & \multicolumn{3}{|c|}{ Group A VS Group C } & & & \multicolumn{4}{|c|}{ Group B VS Group C } \\
\hline L1-L4 & \multicolumn{5}{|l|}{0.220} & \multicolumn{5}{|l|}{0.001} & \multicolumn{4}{|c|}{0.001} \\
\hline L2-L4 & \multicolumn{5}{|l|}{0.144} & \multicolumn{3}{|l|}{0.001} & & & \multicolumn{4}{|l|}{0.001} \\
\hline
\end{tabular}

Results demonstrated the correlation between MRI findings and age, ESR, CRP, T-score, and TBS. A positive correlation was detected between CRP and ESR on one end and BME, depth score, and total MRI score on the other (Fig. 1), while a negative correlation was found between L1-L4 T-score and TBS on one side and BME, depth score, and total MRI score on the other (Fig. 2) and (Fig. 3).

\section{Discussion}

The aim of the current study is to assess BMD and TBS scores in nr-axSpA patients. With regard to baseline characteristics, age was not a factor contributing to differences between the study groups, since it was not significantly different between the 3 studied populations. The results obtained in our study are aligned with the findings of another study [17]. However, findings from our study reveal a higher female-to-male ratio in group A (nr-axSpA) compared to group B (r-axSpA), which is aligned with what has been reported in another study by Kiltz et al [18]. A recent review by Rusman et al attributed the higher ax-SpA burden in females to delay in diagnosis, higher disease activity, and significantly less responsiveness to treatment with tumor necrosis factor inhibitors (TNFis) [19].

Regarding disease duration, our findings indicate a longer disease duration in r-axSpA patients compared with nr-axSpA, which is in agreement with the results obtained elsewhere [20]. Moreover, the German spondyloarthritis inception cohort (GESPIC) of patients suffering from AS found that subjects with longer symptom duration had significantly worse functional scores that was maintained for over 2 years of follow-up [1].

CRP and ESR are acute-phase reactants. It has been highlighted that the former may act as a predictor of radiographic progression [21]. Additionally, higher level of CRP at baseline was found to be associated with improved treatment adherence and superior clinical outcomes [22]. Our results indicate that CRP and ESR levels were significantly higher in groups A and B relative to group C, with no significant differences between the first 2 groups. Additionally, one study demonstrated a higher level of CRP in r-axSpA compared to nr-axSpA. Moreover, CRP level was found to be correlated with MRI inflammation [23].

Results from our study reveal that patients in groups A and B had significantly lower BMI compared with group C. A study by Micheroli et al concluded that BMI affects response to TNFis in axSpA patients, in that study, results demonstrated that obesity was associated with significantly lower response to the aforementioned class of therapeutic agents [24]. Moreover, a French study conducted by Malochet-Guinamand et al found that axSpA patients with lower BMI had lower BMD [25].

A study by Akgol et al concluded that BMD at the lumbar spine was significantly lower in nr-axSpA compared to patients with mechanical low back pain [26]. The results of our study highlighted that patients in the nr-axSpA (group A) had significantly lower BMD and T-scores at L1-L4, femoral neck, and total hip compared to patients in group C (mechanical low back pain group). The inflammatory process was named to be the reason for the lower BMD in nr-SpA patients [26].

TBS is an important imaging technology in assessing bone impairment in axSpA patients. It is a non-invasive technique that provides a reliable method in identifying bone quality deterioration [27]. The results from our study demonstrated that TBS of L1-L4 and L2-L2 
was lower in groups A and B compared to group C. AxSpA patients with lower TBS have been found to be more liable to have vertebral fractures, which makes the tool useful in predicting the future risk of such events [7].

In accordance with what has been described in recent literature, our study revealed the presence of a positive association between TBS and BMD scores of L1-L4, total hip, and femoral neck [28].

There are some limitations in our study. Firstly, the cross-sectional design of our study did not allow us investigate whether TBS can predict the incidence of vertebral fractures. Secondly, we did not collect information regarding the levels of vitamin D.

\section{Conclusions}

We conclude that patients with nr-axSpA have lower BMD and TBS scores compared to patients with r-axSpA and mechanical low back pain. This puts them at a higher risk of fracture. Additionally, good clinical and radiological evaluations along with regular follow-up are warranted among patients with chronic inflammatory back pain to prevent disease progression that could lead to severe irreversible structural changes.

\section{Abbreviations}

\section{SpA}

Spondyloarthritis

AS

Ankylosing spondylitis

axSpA

Axial spondyloarthritis

r-axSpA

Radiographic axial SpA

nr-axSpA

Non-radiographic axial SpA

\section{BMD}

Bone mineral density

TBS

Trabecular bone scores

PsA

Psoriatic arthritis

SIJs

Sacroiliac joints

DXA

Dual-energy X-ray absorptiometry

MRI

Magnetic resonance imaging

SPARCC

Spondyloarthritis Research Consortium of Canada

USA

United States of America

$\mathrm{g} / \mathrm{cm} 2$

gram/ square centimeter

SPSS

Statistical package for social science

SD

Standard deviation

$\mathrm{X} 2$

Chi-square test 
Body mass index

ESR

Erythrocyte sedimentation rate

CRP

C-reactive protein

TNFis

Tumor necrosis factor inhibitors

GESPIC

German spondyloarthritis inception cohort

\section{Declarations}

\section{Acknowledgments}

All authors thank their colleagues at the Rheumatology Department, Al-Azhar University Hospitals as well as Al-Azhar School of Medicine for their fruitful efforts.

\section{Authors' contribution}

IMK was involved in data collection. MMG and MAA were involved in the article drafting. HSH was involved in critical revision of the article. All authors read and approved the final manuscript.

\section{Funding}

No funding was received for this study.

\section{Availability of data and materials}

All data generated or analyzed during this study are included in this published article.

\section{Ethics approval and consent to participate}

Informed consent was obtained from all patients included in the study and approved by medical ethical committee of Al-Azhar University hospital, Damietta branch.

\section{Consent for publication}

Not applicable.

\section{Competing interest}

The authors declare that they have no competing interests.

\section{References}

1. Ghosh N, Ruderman EM. Nonradiographic axial spondyloarthritis: clinical and therapeutic relevance. Arthritis Res Ther. 2017. doi:10.1186/s13075-017-1493-8.

2. Poddubnyy D. Axial spondyloarthritis: is there a treatment of choice? Ther Adv Musculoskelet Dis. 2013. doi:10.1177/1759720X12468658.

3. Robinson PC, Sengupta R, Siebert S. Non-Radiographic Axial Spondyloarthritis (nr-axSpA): Advances in Classification, Imaging and Therapy. Rheumatol Ther. 2019. doi:10.1007/s40744-019-0146-6.

4. Wang R, Ward MM. Epidemiology of axial spondyloarthritis: an update. Curr Opin Rheumatol. 2018. doi:10.1097/BOR.0000000000000475. 
5. Kim HR, Hong YS, Park SH, Ju JH, Kang KY. Low bone mineral density predicts the formation of new syndesmophytes in patients with axial spondyloarthritis. Arthritis Res Ther. 2018. doi:10.1186/s13075-018-1731-8.

6. Schett G. Structural bone changes in spondyloarthritis: mechanisms, clinical impact and therapeutic considerations. Am J Med Sci. 2011. doi:10.1097/MAJ.0b013e31820f8b29.

7. Kang KY, Kim IJ, Park SH, Hong YS. Associations between trabecular bone score and vertebral fractures in patients with axial spondyloarthritis. Rheumatology. 2018. doi:10.1093/rheumatology/key027.

8. Briot K, Roux C. Inflammation, bone loss and fracture risk in spondyloarthritis. RMD Open. 2015;1 doi:10.1136/rmdopen-2015000052.

9. Hans D, Barthe N, Boutroy S, Pothuaud L, Winzenrieth R, Krieg MA. Correlations between trabecular bone score, measured using anteroposterior dual-energy $\mathrm{X}$-ray absorptiometry acquisition, and 3-dimensional parameters of bone microarchitecture: an experimental study on human cadaver vertebrae. J Clin Densitom. 2011. doi:10.1016/j.jocd.2011.05.005.

10. Silva BC, Leslie WD, Resch H, Lamy O, Lesnyak O, Binkley N, et al. Trabecular bone score: a noninvasive analytical method based upon the DXA image. J Bone Miner Res. 2014. doi:10.1002/jbmr.2176.

11. Calin A, Porta J, Fries JF, Schurman DJ. Clinical history as a screening test for ankylosing spondylitis. JAMA. 1977;237:2613-14.

12. Maksymowych WP, Inman RD, Salonen D, et al. Spondyloarthritis research Consortium of Canada magnetic resonance imaging index for assessment of sacroiliac joint inflammation in ankylosing spondylitis. Arthritis Rheum. 2005. doi:10.1002/art.21445.

13. Bray TJP, Jones A, Bennett AN, et al. Recommendations for acquisition and interpretation of MRI of the spine and sacroiliac joints in the diagnosis of axial spondyloarthritis in the UK. Rheumatology. 2019. doi:10.1093/rheumatology/kez173.

14. Lukas C, Braun J, van der Heijde D, et al. Scoring inflammatory activity of the spine by magnetic resonance imaging in ankylosing spondylitis: a multireader experiment. J Rheumatol. 2007;34:862-70.

15. van der Heijde $D$, Landewé R, Hermann KG, et al. Is there a preferred method for scoring activity of the spine by magnetic resonance imaging in ankylosing spondylitis? J Rheumatol. 2007;34:871-73.

16. McCloskey EV, Odén A, Harvey NC, et al. A Meta-Analysis of Trabecular Bone Score in Fracture Risk Prediction and Its Relationship to FRAX. J Bone Miner Res. 2016. doi:10.1002/jbmr.2734.

17. Boutroy S, Hans D, Sornay-Rendu E, Vilayphiou N, Winzenrieth R, Chapurlat R. Trabecular bone score improves fracture risk prediction in non-osteoporotic women: the OFELY study. Osteoporos Int. 2013. doi:10.1007/s00198-012-2188-2.

18. Kiltz U, Baraliakos $X$, Karakostas $P$, et al. Do patients with non-radiographic axial spondylarthritis differ from patients with ankylosing spondylitis? Arthritis Care Res (Hoboken). 2012. doi:10.1002/acr.21688.

19. Rusman T, van Vollenhoven RF, van der Horst-Bruinsma IE. Gender Differences in Axial Spondyloarthritis: Women Are Not So Lucky. Curr Rheumatol Rep. 2018. doi:10.1007/s11926-018-0744-2.

20. Benchérifa S, Amine B, El Binoune I, Hmamouchi I, Rostom S, Abouqal R, et al. Radiographic axial versus nonradiographic axial spondyloarthritis: Comparison of the disease activity parameters and the disease activity and functional scores: RBSMR study. Int J Clin Rheumtol. 2019;14:282-87.

21. Bubová K, Forejtová Š, Zegzulková K, et al. Cross-sectional study of patients with axial spondyloarthritis fulfilling imaging arm of ASAS classification criteria: baseline clinical characteristics and subset differences in a single-centre cohort. BMJ Open. 2019. doi:10.1136/bmjopen-2018-024713.

22. Wallman JK, Kapetanovic MC, Petersson IF, Geborek P, Kristensen LE. Comparison of non-radiographic axial spondyloarthritis and ankylosing spondylitis patients-baseline characteristics, treatment adherence, and development of clinical variables during three years of anti-TNF therapy in clinical practice. Arthritis Res Ther. 2015. doi:10.1186/s13075-015-0897-6.

23. Lorenzin $\mathrm{M}$, Ometto $\mathrm{F}$, Ortolan $\mathrm{A}$, et al. An update on serum biomarkers to assess axial spondyloarthritis and to guide treatment decision. Ther Adv Musculoskelet Dis. 2020. doi:10.1177/1759720X20934277.

24. Micheroli R, Hebeisen M, Wildi LM, et al. Impact of obesity on the response to tumor necrosis factor inhibitors in axial spondyloarthritis. Arthritis Res Ther. 2017. doi:10.1186/s13075-017-1372-3.

25. Malochet-Guinamand S, Pereira B, Tatar Z, et al. Prevalence and risk factors of low bone mineral density in spondyloarthritis and prevalence of vertebral fractures. BMC Musculoskelet Disord. 2017. doi:10.1186/s12891-017-1718-7.

26. Akgöl G, Kamanlı A, Ozgocmen S. Evidence for inflammation-induced bone loss in non-radiographic axial spondyloarthritis. Rheumatology. 2014. doi:10.1093/rheumatology/ket385.

Page $10 / 12$ 
27. Caparbo VF, Furlam P, Saad CGS, et al. Assessing bone impairment in ankylosing spondylitis (AS) using the trabecular bone score (TBS) and high-resolution peripheral quantitative computed tomography (HR-pQCT). Bone. 2019.

doi:10.1016/j.bone.2019.01.024.

28. Rajaei A, Amiri A, Farsad F, Dehghan P. The Correlation between Trabecular Bone Score and Lumbar Spine Bone Mineral Density in Patients with Normal and High Body Mass Index. Iran J Med Sci. 2019. doi:10.30476/IJMS.2019.45413.

\section{Figures}

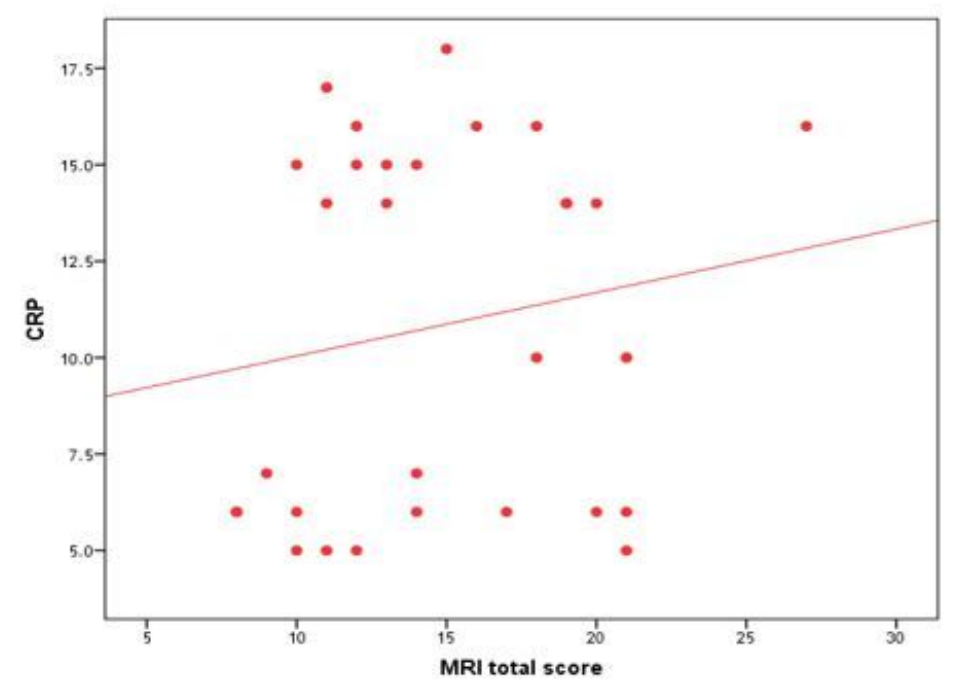

\section{Figure 1}

Positive correlation between CRP and MRI total score. CRP, c-reactive protein; MRI, magnetic resonance imaging.

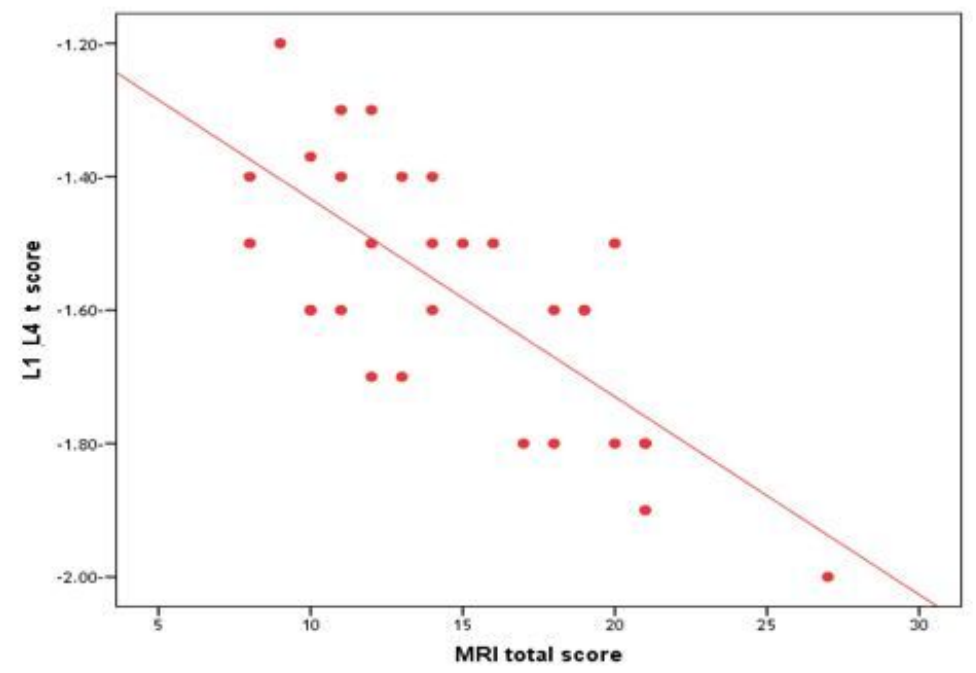

Figure 2

Negative correlation between L1L4 t score and MRI total score. MRI, magnetic resonance imaging. 


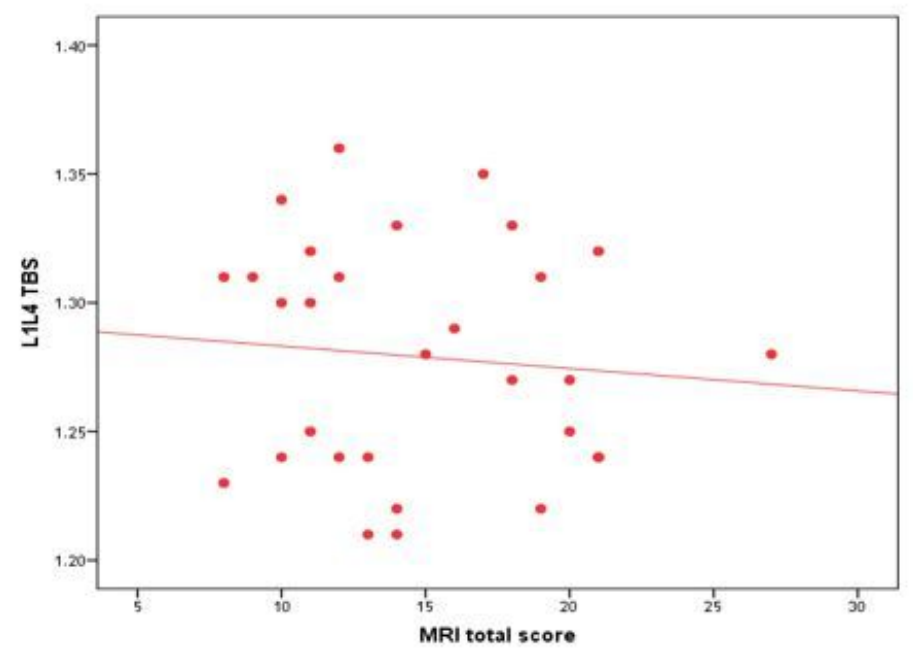

\section{Figure 3}

Negative correlation between L1L4 TBS among MRI total score. TBS, trabecular bone scores; MRI, magnetic resonance imaging. 